\title{
Lack of Impact of Direct-to-Consumer Advertising on the Physician-Patient Encoun- ter in Primary Care: A SNOCAP Report
}

\author{
Bennett Parnes, $M D^{1,2}$ \\ Peter C. Smith, $M D^{1,4}$ \\ Christine Gilroy, $M D^{5}$ \\ Javan Quintela, BS \\ Caroline B. Emsermann, $M S^{1}$ \\ L. Miriam Dickinson, $P b D^{1}$ \\ Jobn M. Westfall, MD, MPH $H^{1,3}$ \\ 'Department of Family Medicine, Uni- \\ versity of Colorado School of Medicine, \\ Aurora, Colorado \\ ${ }^{2}$ Colorado Research Network (CaReNet), \\ Aurora, Colorado \\ ${ }^{3}$ High Plains Research Network (HPRN), \\ Aurora, Colorado \\ ${ }^{4}$ Building InvestiGative practices for better \\ Health Outcomes Research Network (BIG \\ HORN), Aurora, Colorado \\ ${ }^{5}$ Department of Medicine, Division of Gen- \\ eral Internal Medicine, University of Colo- \\ rado School of Medicine, Aurora, Colorado
}

Conflicts of interest: none reported

\section{CORRESPONDING AUTHOR}

Bennett Parnes, MD

Department of Family Medicine

12631 E 17th Ave

AO1 L15, 3rd Floor, F-496

PO Box 6511

Aurora, CO 80045

Bennett.Parnes@uchsc.edu

\begin{abstract}
PURPOSE Direct-to-consumer advertising (DTCA) has increased tremendously during the past decade. Recent changes in the DTCA environment may have affected its impact on clinical encounters. Our objective was to determine the rate of patient medication inquiries and their influence on clinical encounters in primary care.
\end{abstract}

METHODS Our methods consisted of a cross-sectional survey in the State Networks of Colorado Ambulatory Practices and Partners, a collaboration of 3 practice-based research networks. Clinicians completed a short patient encounter form after consecutive patient encounter for one-half or 1 full day. The main outcomes were the rate of inquiries, independent predictors of inquiries, and overall impact on clinical encounters.

RESULTS One hundred sixty-eight clinicians in 22 practices completed forms after 1,647 patient encounters. In 58 encounters (3.5\%), the patient inquired about a specific new prescription medication. Community health center patients made fewer inquiries than private practice patients $(1.7 \%$ vs $7.2 \%, P<.001)$. Predictors of inquiries included taking 3 or more chronic medications and the clinician being female. Most clinicians reported the requested medication was not their first choice for treatment (62\%), but it was prescribed in 53\% of the cases. Physicians interpreted the overall impact on the visit as positive in $24 \%$ of visits, neutral in $66 \%$, and negative in $10 \%$.

CONCLUSIONS Patient requests for prescription medication were uncommon overall, and even more so among patients in lower income groups. These requests were rarely perceived by clinicians as having a negative impact on the encounter. Future mixed methods studies should explore specific socioeconomic groups and reasons for clinicians' willingness to prescribe these medications.

Ann Fam Med 2009;7:41-46. DOI: 10.1370/afm.870.

\section{INTRODUCTION}

7 he average American views 100 minutes of televised direct-to-consumer drug advertising (DTCA) for every minute spent with his or her physician. ${ }^{1}$ Annual DTCA spending during the last decade has seen double-digit growth, outpacing the growth of advertising to physicians, pharmaceutical detailing, and even physician and hospital services. ${ }^{2-}$ ${ }^{4}$ And not without reason: every dollar spent on DTCA increases sales of the advertised drug by an estimated $\$ 2.20$ to $\$ 4.20{ }^{2,5}$ Accordingly, DTCA has become ubiquitous. In a 2002 survey, 92\% of physicians reported that a patient had asked about an advertised drug. ${ }^{5}$ A nationally representative survey in 2003 indicated that one-third of American adults had discussed a DTCA medication with their physician, and that 1 in 10 had received a prescription in response to their inquiry. ${ }^{2}$

Proponents of DTCA suggest it can inform consumers of new therapies ${ }^{6-8}$ motivate them to seek care, ${ }^{8}$ give them more autonomy in weighing 
treatment options, ${ }^{6,7,9}$ and lower drug costs by increasing competition. ${ }^{6}$ Critics argue that DTCA provides incomplete and biased information, ${ }^{10,11}$ leads to inappropriate prescribing, ${ }_{1}^{12}$ increases costs as a result of the added costs of advertising, and consumes time in the physician-patient encounter. 6,13

We know of only 1 previous investigation of patient requests for prescription medications in US primary care clinics conducted in real time at the point of care. ${ }^{14}$ That study, conducted in 2001 using a pointof-care clinician survey, found that in $15.8 \%$ of the encounters, patients requested at least 1 prescription medication. Clinicians prescribed the medication in $80 \%$ of the cases.

Since that time the atmosphere surrounding DTCA has changed considerably. Sparked in part by the withdrawal of Vioxx from the market in 2005, Congress, the Food and Drug Administration, and an increasingly distrustful public ${ }^{15}$ have brought the industry under closer scrutiny, ${ }^{3,16}$ including calls to strictly regulate ${ }^{10}$ or even ban all DTCA. ${ }^{13}$ Given these changes, we conducted a real-time observational study of clinicianpatient encounters among a wide range of primary care clinics in Colorado in 2006. The aim was to determine the rate of patient inquiry for prescription medications, patient and clinician characteristics associated with inquiries, the frequency with which an inquiry led to a prescription, and the impact of the inquiry on various aspects of the clinical encounter.

\section{METHODS}

This study was conducted in 3 practice-based research networks within the State Networks of Colorado Ambulatory Practices and Partners (SNOCAP). The Colorado Research Network (CaReNet) consists of 35 urban and suburban practices that generally care for underserved populations. The High Plains Research Network (HPRN) is an integrated network of 25 practices and other health care facilities in rural Colorado. Building InvestiGative practices for better Health Outcomes Research Network (BIGHORN) consists of 18 private practices throughout Colorado. Combined, these networks include more than 600 clinicians and represent all major demographic populations in Colorado. Practice participation was voluntary.

We developed and pilot tested 2 linked survey instruments before data collection. The first instrument was a brief patient encounter form (Supplemental Appendix 1, available online at http://www.annfammed

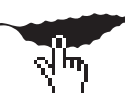
org/cgi/content/full/7/1/41/DC1). Participating clinicians completed this form after each consecutive patient encounter for 1 clinical session (either a full or one-half day). This form elicited information about patient demographics, health, and medications, and whether the patient (or patient's caregiver or surrogate) inquired about a specific prescription medication during the visit. If yes, clinicians responded to additional questions pertaining to the medication and the impact of the inquiry on the clinical encounter.

Clinicians also completed a clinician information form once before seeing patients (Supplemental Appendix 2, available online at http://www. annfammed.org/cgi/content/full/7/1/41/DC1). A unique numeric code protected clinician identity and linked the patient forms with the clinician form. The SNOCAP networks have successfully used this method of data collection previously. ${ }^{17-19}$

We initially analyzed the patient encounter forms and clinician information forms separately. Data were checked for consistency in terms of general responses and responses to questions nested in the forms (questions 7 and 9 from the patient encounter form; question 5 from the clinician information form). On 2 patient encounter forms, responses to question 7 were inconsistent and imputations were therefore performed. No other imputations were made.

We computed descriptive analyses for patient and clinician characteristics. We report means and standard deviations for continuous variables and frequencies and percentages for categorical variables. Because patients may have inquired about more than 1 medication, frequencies and percentages for medications are based on total medications reported. The medication categories were created based on clinical experience. Three authors (B.P., P.C.S., J.M.W.) performed the categorization by consensus.

We computed the primary analyses using all available data ( $n=1,647$ patient encounter forms) in the response to question $7 \mathrm{a}$ on the patient encounter form: "Did the patient inquire about a specific prescription medication?"2 Analyses determined univariate associations between the outcome and all patient and clinician demographic characteristics. In a mixed-effects multivariate logistic regression, we adjusted for analysis characteristics that were significant at the univariate level of $P=.10$. We used mixed-effects models to adjust for the clustering of patients within practices using the SAS analytic software GLIMMIX procedure (SAS Institute, Cary, North Carolina).

Because not all inquiries were for medications that have been advertised in recent years-some medications have long been available as generics (eg, furosemide) -2 authors (J.M.W., B.P.) categorized all listed medications into those that may have been advertised in the last few years vs those without recent advertisements. A second multivariate analysis was performed on this reclassification. 


\begin{tabular}{|c|c|c|}
\hline Characteristic & No. & $\%$ \\
\hline \multicolumn{3}{|c|}{$\begin{array}{l}\text { Age, y (mean } 38.2 \pm 24.6 \text { y; } \\
\text { median } 36 \text { y) }\end{array}$} \\
\hline$<1$ & 59 & 3.6 \\
\hline $1-18$ & 335 & 20.3 \\
\hline $19-49$ & 647 & 39.3 \\
\hline $50-64$ & 286 & 17.4 \\
\hline$\geq 65$ & 273 & 16.6 \\
\hline Missing & 47 & 2.9 \\
\hline \multicolumn{3}{|l|}{ Sex } \\
\hline Male & 567 & 34.4 \\
\hline Female & 1,076 & 65.4 \\
\hline Missing & 4 & 0.2 \\
\hline \multicolumn{3}{|l|}{ Race/ethnicity } \\
\hline White non-Hispanic & 782 & 47.5 \\
\hline Black non-Hispanic & 93 & 5.6 \\
\hline Hispanic & 718 & 43.6 \\
\hline Other & 34 & 2.1 \\
\hline Missing & 20 & 1.2 \\
\hline \multicolumn{3}{|c|}{ No. of active medical problems } \\
\hline 0 & 387 & 23.5 \\
\hline $1-2$ & 659 & 40.0 \\
\hline $3-5$ & 383 & 23.3 \\
\hline$>5$ & 193 & 11.7 \\
\hline Missing & 25 & 1.5 \\
\hline \multicolumn{3}{|c|}{ No. of long-term prescription medications } \\
\hline 0 & 627 & 38.1 \\
\hline $1-2$ & 446 & 27.1 \\
\hline $3-5$ & 287 & 17.4 \\
\hline$>5$ & 264 & 16.0 \\
\hline Missing & 23 & 1.4 \\
\hline \multicolumn{3}{|c|}{$\begin{array}{l}\text { Patient pays entire cost of prescription } \\
\text { medications }\end{array}$} \\
\hline Yes & 203 & 12.3 \\
\hline No & 1,183 & 71.8 \\
\hline Don't know & 159 & 9.7 \\
\hline Missing & 102 & 6.2 \\
\hline
\end{tabular}

Secondary bivariate analyses were computed for patients who inquired about a prescription $(\mathrm{n}=58)$. We used the Fisher exact test to determine associations between demographic and medication request characteristics.

SAS version 9.0 was used for all analyses. All applicable institutional review boards approved the study.

\section{RESULTS}

Twenty-two primary care practices participated in the study, including 8 federally qualified community health centers (CHCs), 5 family medicine residency sites, and 9 private practices. Six practices were rural. There were 17 family medicine practices, 2 general internal medicine, 1 pediatrics, 1 geriatrics, and 1 women's health practice.

A total of 168 clinicians participated. Clinicians
Table 2. Patient $(n=1,647)$ and Physician ( $n=168)$ Characteristics Associated With Requests for Medications

\begin{tabular}{|c|c|c|c|}
\hline Characteristics & OR $^{a}$ & $95 \% \mathrm{Cl}$ & $P$ Value \\
\hline \multicolumn{4}{|l|}{ Patient } \\
\hline \multicolumn{4}{|l|}{ Age, y } \\
\hline$<50$ & 1 & & 0.429 \\
\hline$\geq 50$ & 1.21 & $0.75,1.96$ & \\
\hline \multicolumn{4}{|l|}{ Race/ethnicity } \\
\hline All others & 1 & & 0.051 \\
\hline White non-Hispanic & 1.54 & $1.00,2.38$ & \\
\hline \multicolumn{4}{|l|}{ Chronic medications } \\
\hline $0-2$ & 1 & & 0.001 \\
\hline$\geq 3$ & 2.25 & $1.40,3.62$ & \\
\hline \multicolumn{4}{|l|}{ Clinician } \\
\hline \multicolumn{4}{|l|}{ Sex } \\
\hline Male & 1 & & 0.025 \\
\hline Female & 2.68 & $1.33,5.41$ & \\
\hline \multicolumn{4}{|l|}{ Clinic type $(n=22)$} \\
\hline Community health center & 1 & & 0.025 \\
\hline Residency & 1.32 & $0.55,3.14$ & \\
\hline Private & 3.10 & $1.28,7.47$ & \\
\hline
\end{tabular}

identified their specialty as follows: 128 family medicine $(76.2 \%), 21$ internal medicine $(12.5 \%), 9$ pediatrics $(5.4 \%)$ and 4 other specialties. Of these clinicians, $20.2 \%$ were physician's assistants or nurse-practitioners, and 29.2\% were residents. Excluding residents, the average years in practice after completing training was 11.7 years. Of the 168 clinicians, $62.5 \%$ reported interacting with pharmaceutical representatives. Among those with pharmaceutical representative interactions, $62.9 \%$ had at least 3 interactions per month. A great majority of these clinicians reported that the interactions occurred in outpatient settings $(83.8 \%)$, and $23.8 \%$ said they also attended after-hours pharmaceutical-sponsored dinner presentations.

There were 1,647 survey forms completed by the 168 clinicians, each representing a single clinical encounter. The range of responses per clinician was 1 to 25 . Table 1 displays a description of the patients.

Of the 1,647 patient encounters, 58 (3.5\%) resulted in a specific inquiry about a prescription medication. Patient inquiries occurred in just $1.7 \%$ of $\mathrm{CHC}$ visits compared with $7.2 \%$ of private office visits $(P<.001)$.

In the multivariate logistic regression (Table 2), the greater probability of a medication inquiry persisted for private practices compared with CHCs $\left(\mathrm{OR}=3.10_{\text {; }}\right.$ $95 \% \mathrm{CI}, 1.28-7.47 ; P=.025)$. Also, we found associations between patients' inquiries about a specific medication and (1) patients on more than 3 chronic medications $(\mathrm{OR}=2.25 ; 95 \% \mathrm{CI}, 1.40-3.62 ; \mathrm{P}=.001)$ and (2) female 
Table 3. Types of Medications Requested $(n=62)$

\begin{tabular}{lc}
\hline Category & Number \\
\hline Antimicrobial & 7 \\
Antidepressant & 6 \\
Gastrointestinal & 5 \\
Contraception & 5 \\
Dermatology & 4 \\
Hypnotic and/or benzodiazepine & 4 \\
Nonnarcotic pain medication & 4 \\
Cardiac: blood pressure and lipids & 3 \\
Hypnotic nonbenzodiazepine & 3 \\
Narcotic pain medication & 3 \\
Respiratory & 2 \\
Erectile dysfunction & 2 \\
Osteoporosis & 2 \\
Psychiatric (not listed above) & 2 \\
Steroids & 2 \\
Weight loss & 1 \\
Miscellaneous & 7 \\
\hline
\end{tabular}

clinicians $\left(\mathrm{OR}=2.68 ; 95 \% \mathrm{CI}, 1.33-5.41_{i} P=.025\right)$.

There was evidence of a small physician random effect (ICC $=0.33 ; P=.02$ ) Because of the small number of patients inquiring about a prescription, however, we did not perform hierarchical analyses.

In the second analysis on requested medications that were also advertised, the number of requests fell to 43 (2.6\%). The multivariate analysis performed on this reclassification did not differ substantially from the initial analysis described above.

Four patients requested 2 medications; thus, there were 62 total medications that were requested (Table 3). When a patient inquired about a specific medicine, it was not the clinician's first choice of medication $62 \%$ of the time. The clinician believed the patient wanted the prescription most of the time $(74 \%)$, yet in most cases, the clinician did not feel pressured to prescribe $(66 \%)$. Nevertheless, the clinician prescribed the medication about one-half the time. Clinicians described the overall effect of the patient request as neutral or positive in $90 \%$ of the visits. The specific positive effects far outweighed the reported negative effects (Table 4). In the bivariate analysis, there were no significant associations between patient demographics and medication request characteristics.

\section{DISCUSSION}

In this investigation in Colorado primary care practices, patient inquiries for prescription medications were uncommon (3.5\% of visits). Furthermore, the rate of patient inquiry for advertised products was even lower, $2.6 \%$.
Table 4. Description of Medication Inquiry and Impact on the Clinical Encounter $(n=58)$

\begin{tabular}{|c|c|c|}
\hline Question & No. & $\%$ \\
\hline \multicolumn{3}{|c|}{$\begin{array}{l}\text { How did the patient hear about the medication? } \\
\text { (note: multiple responses allowed) }\end{array}$} \\
\hline Family or friends & 19 & 32.8 \\
\hline Media or advertising & 12 & 20.7 \\
\hline Internet & 2 & 3.5 \\
\hline Other source & 21 & 36.2 \\
\hline Unknown & 6 & 10.3 \\
\hline \multicolumn{3}{|c|}{$\begin{array}{l}\text { Did the patient understand the purpose of the } \\
\text { medication? }\end{array}$} \\
\hline Yes & 56 & 96.6 \\
\hline No & 2 & 3.4 \\
\hline \multicolumn{3}{|c|}{$\begin{array}{l}\text { Would this requested medication have been the } \\
\text { clinician's first choice of treatment? }\end{array}$} \\
\hline Yes & 12 & 20.7 \\
\hline No & 36 & 62.1 \\
\hline No opinion & 10 & 17.2 \\
\hline \multicolumn{3}{|l|}{$\begin{array}{l}\text { Did the patient want a prescription for the } \\
\text { medication? }\end{array}$} \\
\hline Yes & 43 & 74.1 \\
\hline No & 15 & 25.9 \\
\hline \multicolumn{3}{|c|}{$\begin{array}{l}\text { Did the clinician feel pressured to prescribe the } \\
\text { medication? }\end{array}$} \\
\hline Significant pressured & 7 & 12.1 \\
\hline Somewhat pressured & 13 & 22.4 \\
\hline Not pressured & 38 & 65.5 \\
\hline \multicolumn{3}{|l|}{ Was the requested medication prescribed? } \\
\hline Yes & 31 & 53.5 \\
\hline No & 27 & 46.5 \\
\hline \multicolumn{3}{|l|}{$\begin{array}{l}\text { What was the overall effect of the patient } \\
\text { request on the visit? }\end{array}$} \\
\hline Positive & 14 & 24.1 \\
\hline Neutral & 38 & 65.5 \\
\hline Negative & 6 & 10.3 \\
\hline \multicolumn{3}{|c|}{$\begin{array}{l}\text { Specific effects of the inquiry/discussion on the } \\
\text { visit (multiple responses allowed) }\end{array}$} \\
\hline Facilitated discussion & 33 & 55.1 \\
\hline Educated patient & 28 & 48.3 \\
\hline Improved condition awareness & 21 & 36.2 \\
\hline New conditions identified & 6 & 10.3 \\
\hline Increased visit time & 22 & 37.9 \\
\hline Raised insurance concerns & 8 & 13.8 \\
\hline $\begin{array}{l}\text { Negative impact on physician-patient } \\
\text { relationship }\end{array}$ & 3 & 5.2 \\
\hline
\end{tabular}

Our study population included a large proportion of patients of lower socioeconomic status. These patients may be less inclined to request specific medications because medication costs represent a substantial financial burden, and the formulary may be limited, especially in CHCs. In addition, this study included a large proportion of Hispanic patients, many of whom speak only Spanish and thus may have decreased exposure to DTCA. In support of this possibility, white non-Hispanic patients tended to have a higher likelihood of inquiring about specific prescriptions, 
compared with all other groups combined (mostly Hispanics) $(\mathrm{OR}=1.54 ; 95 \% \mathrm{CI}, 1.00-2.38 ; \mathrm{P}=.051)$. The Internet as a source of information about a requested medication was minimal, providing further evidence that the lower socioeconomic status of this population was a factor in the low rate of inquiry. Race, ethnicity, and socioeconomic status may also influence other relational dynamics, such as paternalism, control of the clinical encounter, and patient self-efficacy and self-management.

Even among the private practices, however, our rate of medication inquiries was just $7.2 \%$, less than onehalf the rate $(15.8 \%)$ in a previous report. ${ }^{14}$ Our study was conducted 5 years after the previous report, and it may be that the phenomenon of patient medication requests is declining. Patients may be less trusting of the pharmaceutical industry than before.${ }^{15} \mathrm{Also}$, those patients who are most likely to be exposed to DTCA and request a medication may have already done so at visits before our study period. Alternatively, the lower rate of medication inquiry may reflect recent industry strategies focused on promoting diseases and symptoms (which was not measured in this study), rather than specific medications.

Although clinicians reported that in most cases of medication inquiry, the medication would not have been their first choice for treating the patient's condition and that they felt no pressure to prescribe, the medication was nevertheless prescribed more than one-half the time. This prescribing rate, however, is substantially lower than previously reported $(80 \%) .^{14}$ One explanation for the lower rate is that, because of the lower socioeconomic status of patents in our study, clinicians may have recognized cost as a greater financial burden for the patient. Interestingly, even though clinicians were commonly prescribing medications that were not their first treatment choice, there was an overall negative impact of the medication inquiry in only $10 \%$ of visits. One rich area of future study is the potential opportunity cost of this accommodation to medication requests during visits that are increasingly crowded by other competing demands.

We found that patients were more likely to request medications if they were on a greater number of longterm medications, which is closely associated with the number of chronic conditions. One potential benefit of DTCA is that patient requests may provide the impetus for increased discussion and education about chronic conditions.

It is unclear why female clinicians are more likely than their male counterparts to have medication inquiries in their clinical encounters. It may be a marker for an unmeasured aspect of patient visits promoting patient medication requests, such as a decreased level of paternalism. Surprisingly, other clinician characteristics, such as residency status, specialty, years in practice, or interactions with pharmaceutical representatives, were not associated with inquiries for medications, whether the medication was prescribed, or the overall effect of an inquiry on the visit. Also, we found no association between whether a patient pays full cost for medications and inquiries for medications. One might expect that patients who pay the full cost would be less likely to request medications because of the financial burden.

There are several important limitations to this study. First, most SNOCAP practices did not participate in this project, which might introduce a selection bias. Based on past studies of this type in SNOCAP, however, this participation rate is typical, and we have found that nonparticipation is generally due to clinic circumstances (for example staffing issues) and is unrelated to the study topic. Second, because of the patient population in the SNOCAP clinics, our findings may not generalize elsewhere. SNOCAP includes a wide variety of practices, however, and we believe that our findings are valid for many types of practices.

Third, we did not track the total number of patients seen by clinicians during the data collection period, and thus we cannot provide a response rate. Although it is possible that a clinician would specifically not complete a patient encounter form when there was a patient inquiry because of the extra work, it seems more likely that when the uncommon event of a medication inquiry occurs, the clinician would be more likely to complete the form (since reporting medication inquiries was the purpose of the study). If clinicians did preferentially complete the survey when there was a medication inquiry, then our results would be biased toward a rate that is higher than the true rate. Bias in either direction is likely small, however, because SNOCAP clinicians have become accustomed to responding to this type of point-of-care anonymous survey, making a low response rate unlikely. Because clinicians complete these brief survey forms immediately after the visit, recall bias as a contributor to the low rate of patient inquiries is unlikely.

Finally, it was difficult to determine the extent to which medication inquiries were influenced by advertising. Advertising or media were reported as the proximate source of information for only one-fifth of medication inquiries, but given the ubiquity of drug advertising in the United States today, it is impossible to determine the extent to which other sources of information (eg, family, friends, Internet) were influenced by DTCA as well. If some of the inquiries were not even indirectly related to DTCA, then the overall inquiry rate resulting from advertisements would be even lower. 
We found a low rate of patient medication requests in primary care visits, and many of these requests may not have resulted from DTCA. Clinicians and patients might be growing accustomed to medication requests and DTCA, and DTCA might have less effect among lower income groups. When requests did occur, clinicians generally believed they had an overall neutral or positive impact on the visit. Future studies should target specific socioeconomic groups and replicate this research in other regions. Finally, further investigation of the opportunity costs of using limited clinic visit time on advertised illnesses and medications should be pursued.

To read or post commentaries in response to this article, see it online at http://www.annfammed.org/cgi/content/full/7/1/41.

Key words: Practice-based research networks; direct-to-consumer advertising (DTCA); physician-patient relationship

Submitted October 27, 2007; submitted, revised, May 6, 2008; accepted May 9, 2008.

These findings were presented as an extended paper presentation at the Annual Meeting of the North American Primary Care Research Group, October 28, 2007, Vancouver, British Columbia, Canada.

Funding support: This research was supported by a grant from the Department of Medicine, University of Colorado School of Medicine.

Acknowledgments: The authors would like to thank the clinicians and staff of the 22 participating clinics.

\section{References}

1. Brownfield ED, Bernhardt JM, Phan JL, Williams MV, Parker RM. Direct-to-consumer drug advertisements on network television: an exploration of quantity, frequency, and placement. J Health Commun. 2004;9(6):491-497.

2. Rosenthal MB, Berndt ER, Donohue JM, Epstein AM, Frank RG. Demand Effects of Recent Changes in Prescription Drug Promotion. Menlo Park, CA: The Henry J. Kaiser Family Foundation; 2003.

3. Prescription Drugs: Improvements Needed in FDA's Oversight of Directto-Consumer Advertising. Washington, DC: United States Government Accountability Office; 2006. Report GAO-07-54.
4. Freudenheim M. Showdown looms in congress over drug advertising on TV. NY Times. January 22, 2007.

5. Aikin KJ, Swasy JL, Braman AC. Patient and Physician Attitudes and Behaviors Associated With DTC Promotion of Prescription Drugs - Summary of FDA Survey Research Results. Washington, DC: US Department of Health and Human Services. Food and Drug Administration. Center for Drug Evaluation and Research; 2004.

6. Peyrot M, Alperstein NM, Van Doren D, Poli LG.. Direct-to-consumer ads can influence behavior. Mark Health Serv. 1998;18(2):26-32.

7. Petroshius SM, Titus PA, Hatch KJ. Physician attitudes toward pharmaceutical drug advertising. J Advert Res. 1995;35(6):41-51.

8. Hollon MF. Direct-to-consumer marketing of prescription drugs. JAMA. 1999;281(4):382-384.

9. Bradford WD, Kleit AN, Nietert PJ, Steyer T, Mcllwain T, Ornstein S. How direct-to-consumer television advertising for osteoarthritis drugs affects physicians' prescribing behavior. Health Aff (Millwood). 2006;25(5):1371-1377.

10. Kessler DA, Levy DA. Direct-to-consumer advertising: is it too late to manage the risks? Ann Fam Med. 2007;5(1):4-5.

11. Frosch DL, Krueger PM, Hornik RC, Cronholm PF, Barg FK. Creating demand for prescription drugs: a content analysis of television direct-to-consumer advertising. Ann Fam Med. 2007;5(1):6-13.

12. Spence MM, Teleki SS, Cheetham TC, Schweitzer SO, Millares M. Direct-to-consumer advertising of COX-2 inhibitors: effect on appropriateness of prescribing. Med Care Res Rev. 2005;62(5):544-559.

13. Stange KC. Time to ban direct-to-consumer prescription drug marketing. Ann Fam Med. 2007;5(2):101-104.

14. Mintzes B, Barer ML, Kravitz RL, Bassett K, Lexchin J, Kazanjian A. et al. How does direct-to-consumer advertising (DTCA) affect prescribing? A survey in primary care environments with and without legal DTCA. [see comment]. CMAJ. 2003;169:405-412.

15. Berenson A. Big drug makers see sales decline with their image. NY Times. November 14, 2005.

16. Alina B, Stratton K, Burke SP, eds. Institute of Medicine. The Future of Drug Safety: Promoting and Protecting the Health of the Public. Washington, DC: The National Academies Press; 2007.

17. Parnes BL, Main DS, Dickinson LM, et al. Clinical decisions regarding $\mathrm{HbA} 1 \mathrm{c}$ results in primary care: a report from $\mathrm{CaReNet}$ and HPRN. Diabetes Care. 2004;27(1):13-16.

18. Parnes B, Niebauer $L$, Holcomb S, et al. Provider deferred decisions on hemoglobin $A_{1 c}$ results: a report from the Colorado Research Network (CaReNet) and the High Plains Research Network (HPRN). J Am Board Fam Med. 2006;19(1):20-23.

19. Smith PC, Araya-Guerra R, Bublitz C, et al. Missing clinical information during primary care visits. JAMA. 2005;293(5):565-571. 